\title{
La imagen literaria del extrarradio en la novela española contemporánea (1950-1979)
}

\author{
David GARCÍA PONCE \\ Universidad de Barcelona \\ davidgponce@gmail.com
}

\section{RESUMEN}

El objetivo del artículo es analizar la imagen literaria de los espacios extrarradios en la novela española contemporánea. Siguiendo un recorrido cronológico, se analizan los diferentes periodos y las diferentes estéticas literarias que han contemplado los espacios periféricos de las ciudades de Madrid y Barcelona, a menudo, escenarios de desigualdades y conflictos sociales.

El estudio comienza a finales del siglo XIX, periodo en el cual se ensancha el espacio urbano literario para acudir a los lugares más desfavorecidos. Décadas más tarde, en el medio siglo, se emplean de nuevo técnicas similares con el fin de expresar un desacuerdo con la sociedad del momento y combatir la ausencia de información objetiva acerca de las condiciones de vida en los suburbios. Estos espacios se ven marcados por la renovación de la prosa de los sesenta y a partir de los setenta su presencia en la literatura será discontinua y dejarán de constituir un bloque temático.

Este recorrido permite reflexionar sobre la evolución, los cambios y las características que estos espacios han mantenido en la novela española contemporánea.

Palabras clave: espacios urbanos, extrarradio, suburbio, realismo, Generación del Medio Siglo.

\begin{abstract}
This article examines the literary images of the peripheral areas in the contemporary Spanish novels. By following a chronological order, the article examines the periods and the different literary aesthetics which have often considered these peripheral spaces in the cities of Madrid and Barcelona as places where social inequalities and conflict occurred.

The analysis starts with late $19^{\text {th }}$ century authors as it is the period when writers extend the descriptions of the urban areas and start covering more deprived areas. Eventually, in the fifties writers use this critical similar attitude again to express their disagreement with the society of the moment and to fight the lack of objective information about the real conditions of life in the outskirts. During the sixties, these spaces include the renovation of the prose and from the seventies to the present they have a discontinuous role in the novels. Although the outskirts never become a literary theme, some novels include this periphery. This article helps to examine the evolution, the changes and the characteristics these spaces have in the contemporary novel.
\end{abstract}

Keywords: Urban districts and spaces, periphery, outskirts, realism. 
Cuando Benito Pérez Galdós en La desheredada (1881) describe Las Peñuelas como un barrio el cual «no era una aldea ni tampoco ciudad; era una piltrafa de capital, cortada y arrojada por vía de limpieza para que no corrompiera el centro» ${ }^{1}$, adopta una nueva actitud observadora y crítica que desarrolla con el desplazamiento de los personajes de sus novelas a los barrios del sur de Madrid, donde todas las miserias sociales tenían cabida.

La impresión que tuvo el personaje principal de la obra, Isidora Rufete, cuando piensa que «estaba en la caricatura de una ciudad hecha con cartón podrido» ${ }^{2}$, era más bien todo lo contrario, ya que, con el naturalismo, la ciudad será un escenario multiforme y dejará de ser un telón de fondo ajeno a los personajes y a la diégesis de la obra. Es decir, la novela es el resultado de una observación exhaustiva de la realidad y, a la vez, un testimonio de las condiciones de vida de los lugares más desfavorecidos de la ciudad. Para ello, el autor busca un lenguaje que logre expresar esa realidad con la mayor precisión posible. Se trata de un trabajo de observación que Galdós expone de forma clara para una publicación de Misericordia en 1913:

Me propuse descender a las capas ínfimas de la sociedad matritense, describiendo y presentando los tipos más humildes, la suma pobreza, la mendicidad profesional, la vagancia viciosa, la miseria dolorosa casi siempre, en algunos casos picaresca o criminal y merecedora de corrección. Para esto hube de emplear largos meses en observaciones y estudios directos del natural, visitando las guaridas de gente mísera o maleante que se alberga en los populosos barrios del sur de Madrid ${ }^{3}$.

Estas obras proporcionan un valor documental. Yvan Lyssorgues considera que se impone una «estética de la verdad» ${ }^{4}$ que supone una superación de las técnicas narrativas, en cuanto que muestran una mayor fidelidad en las descripciones y dejan atrás periodos en los cuales la novela ignoraba el extrarradio ${ }^{5}$ «o lo relegaba al campo de lo cómico, o lo toleraba como contrapunto burlesco» ${ }^{6}$. En efecto, el

\footnotetext{
${ }^{1}$ B. Pérez Galdós (1992), p.38.

${ }^{2}$ B. Pérez Galdós (1992), p.57.

${ }^{3}$ Fragmento de «Prefacio de autor escrito especialmente», escrito por Pérez Galdós para una edición de Misericordia publicada en Francia en 1913 (véase Lyssorgues [2012], p. 89).

${ }^{4}$ Y. Lyssorgues (2012), p. 89.

${ }^{5}$ Estos espacios se podrían llamar periféricos al considerar una parte de la ciudad que queda al margen; sin embargo, este término tiene otras aceptaciones no exclusivamente geográficas. Por tanto, emplearemos el término extrarradio, ya que se ajusta al espacio que se analiza en este trabajo. Entendemos por este concepto un área o zona exterior que rodea un núcleo de población que, bien sea por su ubicación o su consideración marginal no quedan dentro de la ciudad y, por tanto, su crecimiento y desarrollo no necesariamente siguen el curso de la urbe donde se ubican.

${ }^{6}$ Y. Lissorgues (2012), p. 83.
} 
naturalismo, por influencia de la filosofía de $\mathrm{H}$. Taine, estrecha los vínculos entre el hombre y el medio en el que vive. Para estos escritores no basta con la imaginación sino que es preciso un conocimiento exhaustivo de la realidad, como lo subraya Matas Pons:

Se rechazaba lo vulgar, lo feo y en consecuencia la representación de los extrarradios, sus personajes dejan de tener un carácter alegórico y pasan a conformar una determinada psicología y un determinado imaginario tanto del individuo como de la sociedad. Son los protagonistas de los procesos revolucionarios que vivirán las ciudades?

Existen muchos estudios sobre espacio y novela y algunos centrados en la novela española. Sin embargo, son escasas las investigaciones que se centran en el estudio de los espacios periféricos y en la evolución que éstos han seguido en la literatura contemporánea. Cubrir este vacío es el principal objetivo de la investigación.

Una de las tareas importantes es identificar las diferentes etapas del siglo XX en las cuales estos topoi tienen notable presencia en la novela. En los primeros años del siglo, Pío Baroja, con su trilogía de La lucha por la vida, innova desde una clara actitud nihilista con las descripciones de los espacios extrarradios y el análisis psicológico de quienes lo habitan. El autor aporta una clara visión antropológica del hampa en una ciudad donde: «La corte es ciudad de contrastes; presenta luz fuerte al lado de sombra oscura; vida refinada, casi europea, en el centro, vida africana, de aduar, en los suburbios» ${ }^{9}$. Contemporánea a la trilogía barojiana es La Horda (1905), de Vicente Blasco Ibáñez, obra que trata las condiciones de vida de los barrios periféricos de la capital.

Sin embargo, en las primeras décadas del siglo XX el panorama intelectual español estará inmerso en un debate entre tradición y vanguardia y los escritores desplazan su atención hacia otros espacios urbanos. Según Cano Ballesta, «la gran empresa de la prosa vanguardista es plasmar en su sorprendente retórica la integración del hombre en la cosmópolis moderna» ${ }^{10}$. Los discursos literarios en torno a la ciudad siguen otros itinerarios urbanos. De hecho, los movimientos vanguardistas elogian el progreso y «quieren poner en contacto las letras con los grandes acontecimientos modernos» ${ }^{11}$. El mundo de la bohemia pasea por el centro y los bajos fondos de la ciudad, acudiendo de forma esporádica a los espacios extrarradios de la ciudad.

\footnotetext{
${ }^{7}$ A. Matas Pons (2010), p. 21.

${ }^{8}$ Trilogía publicada en 1904, constituida por La Busca, Mala hierba y Aurora Roja.

${ }^{9}$ P. Baroja (1997), pp. 53-54.

${ }^{10}$ J. Cano Ballesta (1999), p. 172

${ }^{11}$ J. Cano Ballesta (1999), p.62.
} 
En el caso de Barcelona, según Jordi Castellanos, la novela moderna celebra el esplendor económico ${ }^{12}$ cediendo protagonismo al modus vivendi burgués a la vez que se desplaza a los barrios bajos. El Raval, conocido también como barrio chino, ubicado en los antiguos arrabales de la ciudad, quedará cercano al centro y al barrio burgués de Barcelona y se convertirá en espacio novelesco ${ }^{13}$.

Un panorama diferente representa la novela que surge en las postrimerías de la dictadura. Estas obras «retoman la narración realista pero muy lejos de la considerada tradicional o decimonónica subordinada al discurso de la burguesía» ${ }^{14}$ y el extrarradio, descrito en clave crítica, es el punto de partida hacia los lugares de agitación social que se encuentran en el centro de la ciudad. Representa un desplazamiento inverso al que hacían las novelas del realismo de finales del XIX. Los propios habitantes de la periferia son personajes comprometidos que organizan los levantamientos y escenifican un proceso revolucionario ${ }^{15}$.

Podría ser un buen objeto de estudio analizar si la presencia del extrarradio en los autores del periodo de la República influyó en el grupo de escritores que publican a partir de la década de los cincuenta. Precisamente, el periodo comprendido entre los años 1950 y 1965 es clave para el estudio de la representación literaria de los lugares más desfavorecidos de la ciudad ${ }^{16}$.

Los cincuenta van dejando atrás la autarquía económica y abren paso a un desarrollo económico y a las relaciones con instituciones internacionales. En el

${ }^{12}$ De esta época es muy representativa la novela La ciudad de los prodigios (1986) de Eduardo Mendoza. La obra transcurre por casi todos los espacios de la ciudad entre la exposición de 1888 y la de 1929.

13 J. Castellanos (2002), p. 198.

${ }^{14}$ C. Ricci (2009), p. 188.

${ }^{15}$ Merece la pena destacar la tesis de Sara Muñoz-Muriana: Andando se hace el camino: calle y prácticas formativas del sujeto marginal en la novela española moderna (2012). La autora analiza cómo en el periodo de la II República las masas proletarias se apropian del espacio urbano del centro de la ciudad. De este periodo, analiza en profundidad las obras Siete domingos Rojos (1931), de Ramón J. Sender, y Un hombre de treinta años (1933), de Manuel Benavides. A estas obras se podría añadir Uno (1934), de Andrés Carrenque.

${ }^{16}$ En 1950 se publica en La Hora el artículo de Medardo Fraile «Suburbio no es palabra de domingo», que puede considerarse como pionero en la apertura temática hacia los arrabales por parte de los escritores de la Generación del Medio Siglo, los cuales en los años sucesivos publicarían novelas y en particular cuentos sobre esta temática. Ese mismo año se organiza la semana de cine neorrealista en el Instituto Italiano de Cultura de Madrid. Este evento cultural permite un acercamiento de los intelectuales a la estética neorrealista. Por otro lado, en 1953 nace Revista Española, dirigida por Antonio Rodríguez-Moñino, que sirve a algunos escritores de plataforma para publicar sus trabajos. Este ciclo temático culminaría en los sesenta con la publicación en 1962 de Tiempo de Silencio, de Luis MartínSantos, el ensayo Los otros catalanes de Francisco Candel, en 1964, y Últimas tardes con Teresa de Juan Marsé, en 1966. 
ámbito cultural, surge un grupo de escritores, algunos con formación autodidacta y otros de sólida formación intelectual, que habían vivido la guerra durante su infancia. A estos escritores les unía el afán de novelar la realidad con la mayor precisión posible y dejar constancia de todo cuanto consideran injusto.

La postura de los narradores de la llamada Generación del Medio Siglo frente a los problemas que plantean en la novela no es homogénea. Para algunos, seguidores de un realismo socialista ${ }^{17}$, el valor informativo prima sobre otros propósitos literarios y la implicación en el texto puede ir más allá de la exhaustiva información, en cuanto que apunta a un objetivo de transmitir una ideología. La novela «busca apelar a la conciencia del lector y trata de mostrar [...] las contradicciones radicales de la sociedad en que la novela se produce» ${ }^{18}$. Otros autores, los neorrealistas, influenciados por la estética del cine italiano, adaptan las nuevas técnicas narrativas al propósito de narrar con la misma objetividad que lo haría una cámara fotográfica. Los autores del Medio Siglo ${ }^{19}$ recogen las mejores virtudes de la literatura del fin de siglo y adaptan este magisterio a los argumentos inspirados en los problemas de la sociedad e inquietudes del momento. José Domingo ha señalado algunas pautas formales seguidas por esta generación:

Su tendencia moralizadora, al mismo tiempo que ciertos procedimientos estéticos más o menos comunes, entre los cuales se cuenta preferentemente la tendencia a objetivar sus narraciones, esto es, a presentar sus ficciones desde la base de su entidad física real, sin consideraciones ni juicios del autor, limitado a pasear sobre los hechos la imparcialidad mecánica del objetivo fotográfico, sin intención de ahondar más allá de lo que pueda captarse asi ${ }^{20}$.

Afirmación que complementa Juan Goytisolo:

${ }^{17}$ Empleamos el término realismo socialista según la definición de David Becerra Mayor. Para este autor, el realismo social «estudia los efectos de las condiciones sociales sobre la conducta de los individuos mientras que el realismo socialista visibiliza las contradicciones de la sociedad para transformarla»; en A. López Salinas (2013), p. 49.

${ }^{18}$ A. López Salinas (2013), p. 46.

${ }^{19}$ No entraremos a debatir el nombre oportuno para este grupo ya que ello obligaría a confrontar la opinión de no pocos críticos. Así pues, llamaremos escritores del Medio Siglo, término acuñado por $\mathrm{J} . \mathrm{M}^{\mathrm{a}}$ Castellet, a los autores que se citan en el trabajo y que publicaron sus obras entre 1950 y 1964. Por otro lado, seguiremos la clasificación seguida por Sanz de Villanueva en Historia de la novela social española (1942-1975). Del realismo socialista, aunque el crítico los denomine realistas sociales, citaremos a: Francisco Candel, Juan Goytisolo, Antonio Ferres, Juan García Hortelano, Armando López Salinas, Ramón Nieto, Luis Martín-Santos y Juan Marsé. Dentro del grupo neorrealista citaremos a: Carmen Martín Gaite, Medardo Fraile e Ignacio Aldecoa.

${ }^{20}$ J. Domingo (1973), p.93. 
Los novelistas españoles responden a esa carencia de sus lectores trazando un cuadro lo más justo y equitativo posible de la realidad que contemplan. De este modo la novela cumple con una realidad testimonial que en Francia corresponde a la prensa, y el futuro historiador de la sociedad española deberá apelar a ella si quiere reconstruir la vida cotidiana del país a través de la espesa cortina de humo y silencios de nuestros diarios ${ }^{21}$.

Los cincuenta son años de contradicciones. La prensa está sujeta a un fuerte control institucional, mientras informa con una retórica triunfalista sobre logros y buenas noticias, elude la realidad social del momento; se informa de construcciones públicas y de nuevos barrios, así como de un bienestar generalizado. Sin embargo, la situación en las afueras y la incapacidad de absorber la inmigración de las ciudades no se corresponde con la visión que transmiten los medios informativos. La mirada de los escritores, sensibles a las desigualdades que les rodean, va a retratar las injusticias sociales y todo aquello que los medios de comunicación ocultaban. La hispanista Geneviève Champeau sostiene la idea de que la prensa española de los cincuenta está sujeta a una marcada ideología y carece de información concisa y objetiva ${ }^{22}$.

Uno de estos aspectos eludidos por la miopía informativa es el del crecimiento desenfrenado que viven las ciudades de Madrid y Barcelona por afluencia de inmigrantes procedentes de toda España y que vivirán en condiciones pésimas. Las soluciones planteadas por los organismos oficiales se quedan en un plano teórico que no frena el desarrollo de los suburbios en las afueras de las ciudades. La solución a la carencia de medios para una vivienda será la autoconstrucción -y conviene incidir en esta actividad como medio de supervivencia-, como dirá un personaje de La piqueta: «poniéndoles remiendos poco a poco» ${ }^{23}$, refiriéndose a lugares alejados de la ciudad.

La literatura de esta época se acercará a los suburbios de la ciudad para informar de las condiciones de vida, retratar el drama personal de cuantos viven y expresar, entre líneas, un desacuerdo con la sociedad del momento. Carmen Martín Gaite, en Esperando el porvenir (1984), describe un panorama desolador:

Barrios sin luz eléctrica ni agua corriente. La comida se hacía sobre rudimentarias cocinas de gas butano. Las tertulias, alrededor de las fuentes donde se iba a por agua o en las tabernas que fueron surgiendo. Las gentes llegadas del campo se instalaban primero en casa de parientes, luego compraban una parcelas de 15 a 20 metros cuadrados a un propietario para quien no contaban ni leyes ni ordenanzas

${ }^{21}$ J. Goytisolo (1976), p. 34.

${ }^{22}$ G. Champeau (1995), p. 67.

${ }^{23}$ A. Ferres (2014), p.92. 
y en un par de noches levantaban la chabola, antes de que los guardias pudieran darse cuenta, aunque algunos hacían la vista gorda ${ }^{24}$.

La Generación del Medio Siglo va a dar lugar a una literatura de resistencia que encuentra en los espacios periféricos un espacio de crítica. En efecto, la novela pone el acento en la situación del inframundo de la ciudad, ya que es un topos donde convergen problemáticas entrelazadas: inmigración; explotación del proletariado; diferencias de clases; precariedad de las construcciones; delincuencia; desarraigo; entre otros aspectos. Por tanto, la aportación de la Generación de los 50 representa un arsenal importante para el conocimiento de estos espacios.

Es amplia la nómina de escritores que buscan en el extrarradio madrileño la intención de reflejar una realidad y la de poner en práctica los presupuestos realistas. Atender a todos ellos resultaría un trabajo de gran envergadura. A. Ferres en $L a$ Piqueta (1959) aborda las pésimas condiciones del chabolismo y el problema del desahucio. Ferres pone sobre el papel un tema candente en los cincuenta como es la destrucción de los núcleos de chabolas y la deportación de los inmigrantes sin trabajo fijo a su lugar de origen. Otra obra que aborda el binomio de inmigración y suburbio es La patria sin pan (1962), de Ramón Nieto. La novela narra los problemas con los que se encuentra una familia de Jaén que emigra a Madrid y se instala en un suburbio.

Resulta interesante, por ejemplo, estudiar cómo Juan García Hortelano, autor urbano por excelencia, contrasta los espacios. En el capítulo 8 de Nuevas amistades (1959) el grupo de jóvenes amigos que protagonizan la novela busca a alguien que practique un aborto a Julia más allá del límite sur, donde se extendían los barrios de Chabolas:

Aquello era el poblado, la chata superficie de manchas que, desde la carretera, había supuesto hornos de cal o ruinas. Más allá del alcance de sus ojos, permanecían las chabolas [...]. No había dos edificios iguales, aun siendo todos de un solo piso. La mayoría, enjalbegadas, reflejaban la luz despiadada del sol. Tres calles nacían o acababan en aquel embudo junto a los terraplenes. La más amplia de ellas orientó a Gregorio en el complejo de las chozas, cercas construidas con alambres y trozos de lata, arpilleras colgantes en el hueco de las puertas, ventanas claveteadas de madera y tejados planos, en los que las tejas y las planchas de metal o cemento simultaneaban con otros heterogéneos materiales ${ }^{25}$.

Entre el grupo neorrealista destaca la aportación de Ignacio Aldecoa, quien a través de una aguda observación humana, espacial y lingüística, junto a unas dotes

${ }^{24}$ C. Martín Gaite (1994), p. 95.
${ }^{25}$ J. García Hortelano (1991), pp. 158-159. 
narrativas y un «talante lírico» ${ }^{26}$ unido a una marcada intención crítica, retrata el extrarradio y los personajes que habitan en él. La novela Con el viento solano (1956) recrea las condiciones de vida de las chabolas ${ }^{27}$, pero sobre todo ahonda en este tema a través del cuento. En su amplio repertorio de cuentos, el autor narra las dificultades de vida en los espacios apartados de la ciudad y plasma el sentir de una población desprotegida y la sensación de desarraigo. Destacarían, entre otros, los cuentos: Chico de Madrid (1950), Los atentados del barrio de la cal (1951) y la La tierra de nadie (1961). En el cuento Al otro lado (1953) se observa cómo comienza por un detalle concreto para más tarde ubicar a los personajes en un espacio que con frecuencia es un lugar desfavorecido:

En el interior de la chabola, oscuridad; oscuridad cargada de modorra. Una mujer friega platos metálicos en un cubo. Un hombre duerme, al fondo, tendido en el suelo, la cabeza invisible bajo un periódico abierto a doble plana. Medio cuerpo cubierto con una camiseta agujereada, medio sin tapujos, un chiquillo panzudo se mueve con torpeza de cachorro de un lado a otro [...]. Los enseres son pocos en la chabola: un colchón de saco y paja; algunas cajas vacías; una maleta de cartón roídas las cantoneras; dos cubos; platos de metal y pucheros ahumados; la ropa colgada de un clavo junto a la puerta. [...] La chabola está construida con un trozo de valla, hojalatas, piedras grandes, ladrillos viejos, ramas y papeles embreados, además de otros materiales de difícil especificación. [...] Es la chabola de Martín Jurado y su mujer, una más de las que se extienden a la orilla derecha del río, frente a la ciudad, blanca y hermosa, al otro lado ${ }^{28}$.

Martín Jurado es uno de los tantos inmigrantes que describe Aldecoa como personas que llegan a la ciudad con ilusiones, pero la realidad que les espera será otra:

Sonreía al llegar, pero sus labios están ya demasiado apretados... Ahora sigue dando vueltas por la ciudad. Es un forastero del otro lado del río, hombre que inspira alguna desconfianza. Sabe que primero son los de casa, los de la ciudad, y después él y sus vecinos. Martín se siente extranjero: ellos están fuera de la ciudad, la ciudad tiene fronteras con ellos ${ }^{29}$.

Aldecoa describe la acción como si llevase una cámara filmadora. Las descripciones son simples, sin embargo, el vocabulario empleado es rico y preciso. $\mathrm{Su}$ posición como escritor no es la de brindar una solución a estas historias

\footnotetext{
${ }^{26}$ S. Sanz Villanueva (1980), p. 201.

${ }^{27}$ Las novelas escritas por el grupo de escritores de Madrid suelen emplear el término chabola, mientras que en Barcelona se usa el término barraca.

${ }^{28}$ I. Aldecoa (1973), pp. 242-243.

${ }^{29}$ I. Aldecoa (1973), p. 244
} 
antiheroicas ni la de mostrar «una actitud sentimental ni tendenciosa» ${ }^{30}$, sino narrar con la mayor objetividad posible «una realidad, cruda y tierna a la vez, que está casi inédita en nuestra novela» ${ }^{31}$.

Realidad diferente es la que se vive en Barcelona en los años cincuenta. La ciudad recupera la andadura industrial que había desarrollado a lo largo de todo el siglo XIX. Sin embargo, la observación de los espacios extrarradios es diferente. Barcelona se expresa literariamente por dos vías: desde el exilio o desde una ciudad con tímidos movimientos culturales. Por un lado, la lengua catalana solo se podrá expresar en el exilio y la novela urbana creada en la ciudad se escribe casi exclusivamente en castellano. Se puede decir que la literatura escrita desde el exilio adquiere un tono más intimista, ya que los autores exiliados intentan reparar desde la distancia el impacto vivido. Su visión de la ciudad es muy personalizada. Las descripciones y la trama están basadas en un recuerdo, ilusión o frustración más que en un contacto directo con la realidad de la ciudad. La literatura escrita en castellano toma las riendas del realismo.

No todos los escritores no exiliados tienen interés en acudir a esos espacios de otredad que habían importado nuevas costumbres. A pesar de este vacío temático, destacan dos aportaciones literarias con miradas diferentes hacia el extrarradio: la de Francisco Candel y la de Juan Goytisolo. Candel considera que «novela social es aquella que se circunscribe a los problemas y realidades del obrero. Las novelas sobre otras capas sociales [...] serán novelas testimonio» ${ }^{32}$. Escribe desde el extrarradio, como un habitante más, y recrea la vida de estos espacios con un componente autobiográfico, una acusada crítica social y una hibridación de estilos que van desde la crónica pasando por la autobiografía, entre otros géneros. Donde la ciudad cambia su nombre (1957) es un testimonio de primera mano, es la visión de un escritor que en primera persona describe las condiciones de vida de los barrios de barracas asentados en la falda de la montaña Montjuïc.

La primera etapa de Juan Goytisolo representa un claro ejemplo del realismo social. A través de dos eventos religiosos, el Congreso Eucarístico de 1952 en Fiestas (1958) y la Semana del Suburbio de 1957 en La Resaca (1958), realiza una crítica a las desigualdades de la ciudad y al nacionalcatolicismo. Goytisolo expone la vida de los barrios de barracas que poblaban el litoral de Barcelona. Si bien los temas carecen de originalidad y hay muchos elementos del realismo (un niño que imagina mundos fantásticos, el personaje del trapero, etc.), el autor barcelonés consigue hacer una crítica de la ciudad a través de un sistema de oposiciones

\footnotetext{
${ }^{30}$ Entrevista de R. Vázquez Zamora en la revista Destino, el 3 de diciembre de 1955 (cita recogida en C. Martín Gaite [1994], p. 83).

${ }^{31}$ C. Martín Gaite (1994), p. 83.

${ }^{32}$ S. Sanz Villanueva (1980), p. 153.
} 
espaciales. En sus obras siempre aparece la figura del emigrante, que le servirá de fundamento para crear el personaje del autoexiliado en Señas de identidad (1966).

No solo el suburbio se localiza en las grandes capitales. López Salinas en $L a$ mina (1959) aborda el tema de la explotación obrera. Un grupo de campesinos, afectado por un mal aprovechamiento del campo - que es uno de los temas que el autor critica一, se ve obligado a buscar su porvenir en la explotación de una mina. Estos empleados se ven sometidos a una explotación laboral, malas condiciones de viviendas y de trabajo, hecho que desencadenará un accidente en la propia mina.

La década de los cincuenta constituye el cuerpo principal de este recorrido significativo por los espacios extrarradios. El valor informativo prima sobre otros propósitos. Son obras en las cuales el personaje, como ser individual, ha perdido sus atributos. Ello nos lleva a hablar de un héroe colectivo. Su personalidad representa la de una colectividad. Las historias son lineales y suceden en un periodo corto en unas coordenadas espacio-temporales reducidas, factor que determina la estructura narrativa. La mayoría de las obras transcurren en una realidad coetánea al momento en que son escritas. Para ello es fundamental estudiar las obras con la teoría del cronotopo de Bajtín, donde espacio y tiempo son una unidad indisoluble ${ }^{33}$. Es decir, el espacio urbano ligado a un tiempo concreto:

El tiempo se condensa aquí, se comprime; y el espacio, a su vez, se intensifica, penetra en el movimiento del tiempo, del argumento, de la historia. Los elementos del tiempo se revelan en el espacio, y el espacio es entendido y medido a través del tiempo $^{34}$.

Se trata de un espacio verosímil que puede incluso convertirse en el verdadero protagonista de la novela y determinar al personaje. Es decir, el extrarradio ya determina un tipo $\mathrm{u}$ otro de personaje.

En los años sesenta, época de desarrollismo, la novela hubiera tenido un caudal temático importante, ya que los barrios de chabolas se fueron transformando en polígonos de viviendas que algunos arquitectos y urbanistas han calificado como barracas verticales. Estos polígonos de viviendas no estarán exentos de desigualdades y en la mayoría de los casos carecen de equipamientos sociales. Faltan novelas en las cuales aparezcan las reivindicaciones vecinales, reuniones clandestinas, reuniones y encerronas en las parroquias de las barriadas, así como la figura del párroco, los llamados «curas progres» ${ }^{35}$. Es la época en que las

\footnotetext{
${ }^{33}$ A. Garrido (1996), p. 209

34 J. R. Vallés Calatrava (1999), pp. 12-13.

${ }^{35}$ Estos movimientos vecinales y parroquiales quedan recogidos con rigor histórico en la obra Padre Llanos: un jesuita en el suburbio, J. L. González Balados (1991). En la obra se narra la vida del jesuita José María de Llanos que dedicó parte de su vida a los habitantes de El Pozo del Tío Raimundo en Madrid.
} 
asociaciones vecinales toman un rol importante en la vida de barrio, en el cual conviven dos generaciones y hay una estructura cimentada. Sin embargo, esta realidad social no atrajo el interés de los novelistas, que comenzaban a relegar los presupuestos del realismo en pro de nuevas experiencias narrativas. La mayoría de los críticos lo atribuyen a un agotamiento temático, mientras que Constantino Bértolo habla de un cambio ideológico en la época del desarrollismo por parte de una burguesía que abandona el proceso revolucionario para postularse en la socialdemocracia ${ }^{36}$.

No obstante, en esta década se publican dos obras que realizan una mirada retrospectiva hacia los extrarradios de la posguerra. Un tema recurrente de la década anterior que se adapta a la renovación de la prosa de los sesenta. La publicación de Tiempo de Silencio de Luís Martín-Santos, en 1962, y Últimas tardes con Teresa de Juan Marsé, en 1966, supone una incorporación en la prosa de tendencias experimentales y renovadoras que no abandonan la denuncia de las estructuras socio-económicas del país, ni tampoco dan la espalda a la problemática social que había inquietado a la Generación del Medio Siglo. Estos autores integran la cartografía de la pobreza en la realidad social de la ciudad y la contraponen a los barrios burgueses o de clase media. Funden los análisis psicológicos de los personajes con la interpretación crítica de sus actos, que oscila entre el escepticismo y el desengaño. Frente a la técnica del diálogo y la acción, los autores crean una narración minuciosa que alcanza un tono personal y subjetivo, narran la realidad al tiempo que la juzgan. Así pues, los espacios van íntimamente ligados a los personajes, los cuales alcanzan una gran entidad, ya que desaparece el personaje colectivo. El autor deja de fotografiar los suburbios para entrar en ellos y para dialogar con sus personajes desde su retórica personal.

Juan Benet definió a Martín-Santos como una persona que «abandonó las filas de la tradición ortodoxa para formar parte de la heterodoxia» ${ }^{37}$. El autor vasco aporta una innovación técnica basada en una pluralidad de estilos, desde el monólogo interior, el flujo de la consciencia, etc. Martín-Santos emplea una crítica contra el ethos español y sus mitos. Trastoca las estructuras tradicionales y denuncia a través de una labor desmitificadora. El autor de Tiempo de Silencio no solo innova con sus técnicas, sino que también acude a la tradición anterior para crear elementos renovadores en el presente. La obra representa una experimentación que abrirá una nueva etapa. El extrarradio de Madrid es el reflejo de una sociedad desigual: «Sobre un pequeño montículo en que concluía la carretera derruida [...] florecían pegados, pegados, los unos a los otros, los soberbios alcázares de la miseria» ${ }^{38}$. Un espacio que hasta ese momento no se había retratado de forma tan audaz con un excelente

\footnotetext{
${ }^{36}$ A. López Salinas (2013), pp. 88-89.

${ }^{37}$ J. Benet (1987), p. 117.

${ }^{38}$ L. Martín-Santos (1989), p. 50.
} 
juego de metonimias. El protagonista descubre el suburbio y el narrador aprovecha para hacer una denuncia social, que llevará a cabo a través de una clara influencia barojiana y un estilo faulkneriano, que está presente en toda la obra y se alejará de los presupuestos del realismo social. La obra critica las diferencias entre centro urbano y periferia. Ambientada en 1949, en los «años del hambre», presenta el inframundo con ironía entre basuras como recurso de denuncia del progreso:

Estas chabolas marginales y sucias no pretendían ya como las otras tener siquiera apariencia de casitas, sino que se resignaban a su naturaleza de agujero maloliente sin pretensiones de dignidad ni de amor propio en estricta correlación con la vida de sus habitantes ${ }^{39}$.

Últimas tardes con Teresa plantea, con vetas poéticas, un sistema de oposiciones entre las diferentes realidades que se viven en la Barcelona de la postguerra: la de una burguesía que vive un desarrollo económico y la de unos barrios marginales donde viven inmigrantes que siguen siendo víctimas de condiciones pésimas de vida. Esta burguesía vivía al margen de cuanto acontecía en el extrarradio, y cuando estos espacios formaban parte de sus conversaciones normalmente lo hacían en tono despectivo:

Para la señora Serrat, el Monte Carmelo era algo así como el Congo, un país remoto e infrahumano, con sus leyes propias, distintas. Otro mundo. A través de la luminaria azul de su vida presente, a veces aún le asaltaban lejanos fogonazos rojos: un viejo cañón antiaéreo disparando desde lo alto del Carmelo y haciendo retumbar los cristales de las ventanas de todo el barrio (entonces, cuando la guerra, vivían en la barriada de Gracia, y al horrendo cañón al que la gente lo llamaba el «Abuelo»). [...] Eran hijos de refugiados de la guerra, golfos armados con tiradores de goma y hondas de cuero, y rompían faroles y se colgaban detrás de los tranvías. Pensando en ello, ahora le dijo a su hija:

- Tú ya no te acordarás, pero cuando eras una niña, un salvaje del Carmelo estuvo a punto de matarte... ${ }^{40}$.

Despectiva es también la mirada de la burguesía hacia los inmigrantes. A menudo se les llamaba murcianos, una denominación que no hacía mención a la región geográfica de Murcia sino a un inmigrante de origen no catalán. No obstante, desde los años veinte, a los inmigrantes procedentes de otras regiones de España se les denominará también charnegos ${ }^{41}$. Uno de estos charnegos es Manolo Reyes, el

\footnotetext{
${ }^{39}$ L. Martín-Santos (1989), p. 69.

${ }^{40}$ J. Marsé (2010b), p. 198.

${ }^{41}$ Charnego o Xarnego hace alusión, generalmente en tono despectivo, a una persona residente en Cataluña de padres procedentes de otras regiones españolas y que emplea la lengua castellana como idioma vehicular. El escritor Francisco Candel dedica un capítulo de
} 
«pijoaparte» que junto con Teresa Serrat es el personaje principal de la obra. El protagonista de la obra tiene una clara inspiración en el personaje de Julien Sorel de Stendhal; ambos tienen el firme propósito de abandonar su estatus de pobreza y mejorar la condición social. El «pijoaparte» se ha considerado por la crítica como uno los personajes que se han convertido en arquetipo de una condición social; en las primeras páginas de la obra el autor pone de relieve cómo estas personas son vistas por los oriundos de la ciudad: «Pero también había zonas tenebrosas: él no ignoraba que su físico delataba su origen andaluz - un xarnego, un murciano (murciano como denominación gremial, no geográfica: otra rareza de los catalanes)— ${ }^{42}$.

Según Rodríguez Fischer, «un rasgo clave de la narrativa de Marsé es el tratamiento del espacio y su función sustentadora de una trama» ${ }^{43}$, y la autora añade:

Es un espacio vivencial, un espacio cerrado que confiere identidad e ideología a quienes lo habitan. [...] El espacio en el que se mueven los personajes de Juan Marsé es más bien un espacio mental, un barrio inventado que no se corresponde exactamente con la realidad urbana de Barcelona, aunque esté repleto de detalles y nombres reales ${ }^{44}$.

Se puede decir que, en la obra de Marsé, hay una clara correlación entre topografía y personaje. La novela es deudora de su orografía. No sería la misma sin las montañas que rodean la ciudad y que permiten una mirada desde el suburbio hacia la ciudad.

Los setenta no parecen muy interesados en estos espacios. Se aprecia una evolución urbanística en los alrededores de las grandes ciudades que continúan siendo hervideros de tensiones sociales. Estos espacios los recuperan la novela negra y el cine. En ambos géneros prolifera la llamada «estética del desencanto», que es una posición crítica y desfavorable al curso político y social que siguen los cambios de la dictadura a la democracia. Es precisamente en el periodo de transición cuando prolifera la novela negra siguiendo una estética realista, una narratividad de los hechos que apartaba el experimentalismo de los años anteriores y una intención de acudir a las lacras sociales y dejar testimonio de ello. Por un lado, la novela plantea nuevos temas y por otro el cine toma el relevo de esta temática. Autores como Andreu Martín en Barcelona o Juan Madrid en la capital acuden a los

su obra Los otros catalanes (1964) a esta cuestión. Para Candel, charnego es aquel que no habla catalán, ya que una persona no nacida en Cataluña pero integrada lingüísticamente no provoca un rechazo entre la población nativa. Prueba de ello es que el nombre se extendió en las áreas donde la inmigración no se adaptó culturalmente.

${ }^{42}$ J. Marsé (2010b), p. 23.

${ }^{43}$ J. Marsé (2010a), p.64.

${ }^{44}$ J. Marsé (2010a), pp. 64-65. 
barrios decadentes siempre con la poética del género negro. Estas novelas inciden en la realidad social presentándola a través de un mundo de ficción, con antihéroes desencantados $\mathrm{y}$, en ocasiones, desengañados de cualquier esperanza de futuro. Recurren a lo cotidiano y a la cultura popular. La novela negra representa la parte oscura de la sociedad y esta se puede encontrar en los extrarradios de las ciudades.

Es aquí donde entra en escena Manuel Vázquez Montalbán, que va de los bajos fondos al extrarradio. El polifacético autor reivindica estos espacios. En este contexto, una de sus obras principales es Los mares del sur (1979), en la cual Montalbán critica la corrupción urbanística, el enriquecimiento de algunos burgueses que construyeron polígonos de viviendas de pésima calidad, y expone las luchas reivindicativas, el peso de las asociaciones vecinales y las revueltas sociales. Montalbán describe estos espacios como hervideros de tensiones sociales en clave de desencanto:

A finales de los años cincuenta, y dentro de la política de expansión especulativa del alcalde Porcioles, la sociedad Construcciones Iberisa compra a bajo precio descampados, solares donde se ubicaba alguna industria venida a menos y huertos familiares del llamado Camp de SantMagí, zona dependiente del municipio de L'Hospitalet [...]. Fue mayoritariamente poblado por proletariado inmigrante. El alcantarillado no quedó totalmente instalado hasta cinco años después del funcionamiento del barrio. Falta total de servicios asistenciales. Reivindicación de un ambulatorio del seguro de enfermedad. De diez a doce mil habitantes. Menuda pieza estabas hecho Stuart Pedrell. [...] Todo el barrio sufre inundaciones cuando se desbordan las canalizaciones del río Llobregat ${ }^{45}$.

La visión desencantada del detective Carvalho se dirige hacia una violencia socio-espacial, mientras que el crimen es una escena simbólica. Analiza la expansión de la ciudad en una época de desregularización, en palabras de Resina: «la violencia del régimen político queda registrada en las cicatrices de la ciudad» ${ }^{46}$.

Entre los años setenta y ochenta, el cine releva a la literatura en la representación de los extrarradios. Se produce un tipo de cine, conocido como cine Quinqui, que representa la vida de la segunda generación de las barriadas periféricas. Estas producciones centran su atención en la conflictividad social -delincuencia, drogadicción, etc. - en ocasiones estereotipada. En las décadas sucesivas, la representación de los barrios periféricos no supone un bloque temático individual, sino que responde a un criterio personal del autor y su presencia en la novela actual es anacrónica. Como otros temas, su representación ha acogido algo muy característico de las últimas tendencias novelísticas, como es la hibridación de

\footnotetext{
${ }^{45}$ M. Vázquez Montalbán (1979), p. 106-107.

${ }^{46}$ J. R. Resina (1997), p. 167.
} 
estilos y, como en épocas anteriores, relacionando diferentes temas de índole social $^{47}$.

Resulta evidente que la selección de obras y autores no es completa. En realidad, la selección pretende poner de relieve la importancia de los espacios extrarradios en la novela española contemporánea y sus diferentes maneras de representación. Quedan en el tintero autores y obras que podrían quedar incluidos en un estudio más exhaustivo.

El eje cronológico y los ejemplos analizados demuestran la evolución estilística en la representación de estos espacios. No obstante, se ha podido comprobar cómo existe una filiación entre la estética realista y el extrarradio. A su vez, se constata cómo en los periodos en los cuales el propósito del escritor es el de atender a los problemas sociales, cualquiera que sea su implicación, se acude a los espacios deprimentes, ya que en estos se entrelazan muchos problemas sociales.

Estos espacios acostumbran a estar ubicados en una gran ciudad, por lo general industrial. La topografía de la ciudad determina la evolución y forma del extrarradio y la relación con el centro de la ciudad. Estos espacios no tienen una ubicación estática. Así pues, la condición mutante es una de las características principales, como bien explica el personaje de Mariana a Sofía en Nubosidad variable:

Te escribo sentada en un compartimento de coche-cama, mientras al otro lado de la ventanilla se suceden barriadas modestas, cementerios de coches, huertas, fábricas, desmontes, vertederos de basura y chatarra y esos grupos de chabolas que se van desplazando cada día más allá, propagándose como los labios de una llaga, a medida que los especuladores con sus excavadoras hacen batirse en retirada a la miseria del extrarradio, como si quisieran negarle la existencia al apartarla de su vista. El sol se estaba poniendo justo al salir de la estación de Atocha, pero todavía quedan sobre las nubes oscurecidas algunos resplandores de color naranja $^{48}$.

${ }^{47}$ Merece la pena citar a algunos autores como Francisco Casavella, que representó la vida de los barrios marginales en el periodo de la transición a la democracia. Por otra parte, Francisco Umbral publicó en los noventa Madrid 650. Este autor había reivindicado en varios artículos el olvido por parte de las instituciones del extrarradio. En esta obra crea un barrio, La Hueva, y un personaje, Jerónimo, a través de los cuales el autor expone el problema de la droga en los extrarradios de la capital. En Barcelona podemos señalar a Javier Pérez Andújar, con sus obras Los príncipes Valientes (2007) y Paseos con mi madre (2011). Ambas obras están escritas en clave autobiográfica y recrean la infancia y adolescencia en una población del extrarradio barcelonés. En los últimos años se han creado diferentes blogs que recuperan estos espacios de memoria o critican la situación del extrarradio en este contexto. Entre estos destacaría el de la escritora Elvira Navarro: Periferia.

${ }^{48}$ C. Martín Gaite (1992), p. 51. 
Aquellos espacios que hace décadas eran extrarradios hoy pueden pertenecer a un núcleo urbano. En cualquier caso, estos espacios siempre tienen una frontera física - un descampado, un puente, la línea del tren, etc.- o imaginaria en la mente del autor, que ve la ciudad como algo tan lejano como ajeno a la realidad del extrarradio. En muchas de las novelas hay una oposición binaria entre centro y periferia.

El estudio de la representación literaria del extrarradio, por un lado, aporta un conocimiento de la historia que no siempre se puede obtener por otros medios. Por otro lado, tiende a un diálogo interdisciplinar, ya que es preciso acudir a estudios de urbanismo, sociología, antropología, etc.

Lo expuesto hasta el momento lleva a plantear si verdaderamente se puede hablar de una literatura de suburbio o extrarradio. Matas Pons, en su estudio sobre literatura y ciudad afirma:

La novela del suburbio es, sobre todo, una escritura suburbial de aquella gran tradición moderna de las letras europeas que representaba una realidad cambiante y fragmentaria. Ya no tiene sentido la representación del espacio urbano como un escenario estático y monocromo donde proyectar la figura de un único héroe de acción ${ }^{49}$.

Si bien hay un imaginario común - descampado, hampa, delincuencia, chabola, polígonos de viviendas, etc.- - los argumentos de las obras pueden ser variados y el espacio puede ser tratado desde estilos diferentes - autobiográfico, crónica, etc.- . Se puede decir que el extrarradio es un paradigma de la realidad cambiante de una ciudad y de una sociedad. No obstante, y como hemos podido estudiar, tiene unas características que lo separan del centro de la ciudad y representa un objeto de estudio literario importante, en cuanto que estos espacios se han ido adaptando a las diferentes estéticas de la novela contemporánea sin necesidad de constituir un género propio.

\section{OBRAS CITADAS}

ALDECOA, Ignacio: Cuentos completos, Madrid, Alianza Editorial, 1973.

BAROJA, Pío: La busca, Madrid, Caro Reggio, 1997.

BENET, Juan: Otoño en Madrid hacia 1950, Madrid, Alianza Editorial, 1987.

CANO BALlestA, Juan: Literatura y tecnología. Las letras españolas ante la revolución industrial (1890-1940), Valencia, Pre-textos, 1999.

${ }^{49}$ A. Matas Pons (2010), p. 137. 
CASTEllanos, Jordi: «Barcelona, las tres caras del espejo: del Barrio Chino al Raval», Revista de Filología Románica, Anejo 3 (2002), pp. 189-202.

CHAMPEAU, Geneviève : Les enjeux du réalisme dans le roman sous le franquisme, Madrid, Casa de Velázquez, 1995.

DOMINGO, José: La novela española del siglo XX, Barcelona, Labor, 1973.

FERRES, Antonio: La Piqueta, Madrid, Gadir, 2014

GARCíA HoRTElano, Juan: Nuevas amistades, Madrid, Taurus, 1991.

GARrido DomíngueZ, Antonio: El texto narrativo, Madrid, Síntesis, 1996.

GONZÁLEZ BALADOS, José Luis: Padre Llanos: un jesuita en el suburbio, Madrid, Temas de hoy, 1991.

Goytisolo, Juan: El furgón de cola, Barcelona, Seix Barral, 1976.

LÓPEZ SALINAS, Armando: La mina, David Becerra (ed.), Madrid, Akal, 2013.

LYSSORGUES, Yvan: «Los espacios urbanos de la miseria en algunas novelas del siglo XIX. Una estética de la verdad», Anales de la literatura Española, 24 (2012), pp. 83-109.

MARSÉ, Juan: Si te dicen que caí, Ana Rodríguez Fischer y Marcelino Jiménez León (ed.), Madrid, Cátedra, 2010a.

: Últimas tardes con Teresa, Barcelona, Ediciones DeBolsillo, $2010 \mathrm{~b}$.

MARTín GAITE, Carmen: Nubosidad variable, Barcelona, Anagrama. 1992. : Esperando el porvenir, Madrid, Siruela, 1994.

MARTín-SANTOS, Luis: Tiempo de Silencio, Barcelona, Seix Barral, 1989.

MATAS PONS, Álex: La ciudad y su trama: literatura, modernidad y crítica de la cultura, Madrid, Lengua de Trapo, 2010.

MUÑOZ-MURIANA, Sara: Andando se hace el camino: calle y prácticas formativas del sujeto marginal en la novela española moderna, Tesis doctoral dirigida por Ángel G. Loureiro, Princeton NJ, Princeton University, 2012.

PÉREZ GAldós, Benito: La Desheredada, Barcelona, Planeta, 1992.

RESINA, Joan Ramón: El cadáver en la cocina: la novela criminal en la cultura del desencanto, Barcelona, Anthropos, 1997.

RICCI, Cristian H.: El espacio urbano en la narrativa del Madrid de la Edad de Plata (1900-1938), Madrid, CSIC, 2009.

SANZ VillanueVa, Santos: Historia de la novela social española (1942-75), Madrid, Alhambra, 1980.

VALlÉS CALATRAVA, J. R.: El espacio en la novela. El papel del espacio narrativo en La ciudad de los prodigios de Eduardo Mendoza, Almería, Universidad de Almería, 1999.

VÁZQUeZ MonTALBÁn, Manuel: Los mares del sur, Barcelona, Planeta, 1979. 